\title{
Preliminary assessment of the gender aspects of disaster vulnerability and loss of human life in South Africa
}

\author{
Authors: \\ Roman Tandlich ${ }^{1}$ \\ Tatenda Grace Chirenda \\ Chandra Sekhar Sunitha \\ Srinivas ${ }^{2}$ \\ Affiliations: \\ ${ }^{1}$ Division of Pharmaceutical \\ Chemistry, Faculty of \\ Pharmacy, Rhodes University, \\ South Africa \\ ${ }^{2}$ Division of Pharmacy \\ Administration and Practice, \\ Faculty of Pharmacy, Rhodes \\ University, South Africa \\ Correspondence to: \\ Roman Tandlich \\ Email: \\ r.tandlich@ru.ac.za \\ Postal address: \\ PO Box 94, Grahamstown \\ 6140, South Africa \\ Dates: \\ Received: 06 Sept. 2012 \\ Accepted: 11 Jan. 2013 \\ Published: 18 Mar. 2013 \\ Keywords: \\ disaster-related fatalities; \\ gender-adjusted death \\ rates; South Africa; literacy \\ inequality; maternal \\ healthcare \\ How to cite this article: \\ Tandlich, R., Chirenda, T.G. \\ \& Srinivas, C.S.S., 2013, \\ 'Preliminary assessment \\ of the gender aspects of \\ disaster vulnerability and loss \\ of human life in South Africa', \\ Jàmbá: Journal of Disaster \\ Risk Studies 5(2), Art. \#84, \\ 11 pages. http://dx.doi. \\ org/10.4102/jamba.v5i2.84

\section{Note:} \\ 1st Biennial Conference, \\ Southern African Society for \\ Disaster Reduction (SASDiR), \\ 09 to 11 October 2012, \\ Potchefstroom, South Africa \\ Read online:

South Africa has reached a medium level of human development and has a heterogeneous situation with respect to disaster risk management. In this article, a preliminary assessment of the gender aspects of disaster vulnerability and fatalities is presented. The United Nations, the Health Systems Trust and Statistics South Africa were used as data sources for the following gender-segregated values: the life expectancy at birth, unemployment rates, the human development index values, the maternal mortality rates and the number of deaths from unnatural and non-natural causes. The relevant inequality indices were then calculated and used to draw conclusions regarding the gender aspects of disaster risk management in South Africa. Results of the calculations indicate that between 1980 and 2011 men were $10 \%$ more vulnerable with respect to their health status. However, the gender differences have been decreasing in recent years. Access of women to healthcare is decreasing with time, potentially decreasing the recovery potential of whole families. Women are more economically vulnerable than men in South Africa, as they are 16.3\% - 33\% more likely to be unemployed than men. Educational status of both genders in South Africa is comparable based on literacy and enrolment rates at primary and secondary level. On the other hand, men are five times more likely to suffer fatal injuries during disasters.

\section{Introduction}

South Africa's total population reached 50.46 million in 2011, and is predicted to grow by $0.5 \%$ per annum between 2010 and 2015 (United Nations Statistical Indicators 2012). The country currently ranks 14th globally for men and 18th for women with respect to the life expectancy at birth (United Nations Statistical Indicators 2012). Even though it has reached a medium level of human development (Human Development Index [HDI]) (UNHDI 2012), South Africa still ranks among the bottom 30 nations globally with respect to the population's ability to provide satisfactory food and shelter at the household level (The Legatum Prosperity Index 2011). Maleheaded households have a $28 \%$ probability of being poor whilst the figure almost doubles, at $48 \%$, for their female-headed counterparts (South African Regional Poverty Network 2011). This is alarming as savings at the household level are low and estimated at $20 \%$ of the gross domestic product (GDP) (The Legatum Prosperity Index 2011). These figures indicate that economic poverty levels are potentially high in South Africa. At the same time, food security and sufficient shelter will not be available to a large segment of the South Africa population, indicating that the South African population could potentially be highly vulnerable to disasters.

South Africa's geographical location, climate and other relevant factors make the country prone to flooding, drought, tornadoes and earthquakes (Prevention Web 2011). Multiple factors control disaster risks and the vulnerability of the population (International Society of Red Cross and Red Crescent Societies 2000). A correlation is likely to exist between health and economic status and the population's ability (and willingness) to evacuate from a disaster area (Nigg, Barnshaw \& Torres 2006). The population's health and nutritional standing will control their susceptibility to communicable diseases occurring in the aftermath of a disaster (Luyt et al. 2011). Low literacy and the resulting lack of awareness increase the severity of disaster impacts on the population (Haque et al. 2012). In addition, variables such as gender distribution of the residents must be taken in account during the disaster risk management (DRM) cycle (Enarson 2001).

The above-mentioned factors are linked to the social and/or disaster vulnerability. This vulnerability originates from a combination of the health status of the population, limited access to knowledge, economic assets, the types of dwellings used, lifelines, political influence, cultural traditions and infrastructural development in a particular area (Blaikie et al. 1994; Cutter 2001; Putnam 2000; Tierney, Lindell \& Perry 2001). It is a function of the population characteristics such as 'age, gender, race, and socioeconomic status' (Cutter, Boruff \& Shirley 2003). Analysis 
of census and related statistical data in the United States has shown that the major parts of vulnerability are rooted in the financial wealth and age structure of the population, density of built-up areas, the structure and ownership of the housing infrastructure in a particular area, race group of the given segment of the population, belonging to a particular ethnic group, and the job profile of the population (Cutter et al. 2003). Such an evaluation is needed to enable South Africa to identify the segments of the population that are going to be most vulnerable during disasters. Data for this assessment are extracted from national and international databases (see below). This in turn will facilitate an effective DRM planning strategy for South Africa.

Gender is a social construct which originates from the societal roles of men and women, and the norms of a given society (Food and Agricultural Organisation of the United Nations 1997). Tribal chieftains and other traditional leaders have strong influence in the daily lives of South African communities (Kapfudzaruwa \& Sowman 2009; Mashele 2004). Traditions therefore play a significant role in South Africa, leading to a misconstrued understanding of sex and/or gender (Nyalunga 2012). Similar interchangeability is observed in the published statistical data and therefore both of these facts are taken into account in this article. Sex is defined based on a number of biological criteria that are accepted by a given society (West \& Zimmerman 2002). Everyday application of the sex criteria and displays of characteristic behaviour define sex categories, and gender then results from the management and conduct along the lines of "'normative conceptions of attitudes and activities" in line with one's sex category' (West \& Zimmerman 2002). These three notions and norms often dictate the situations in which a person will find him- or herself (West \& Zimmerman 2002).

Another definition of gender or heterogender is the 'stratification of sexes' with respect to the developing notion of 'patriarchal heterosexuality', which is related to the division of labour along sex lines (Ingraham 2002). In this context, gender is seen as 'the cultural side of sex', and the term gender thus provides a description of the mutual social relationship between men and women (Ingraham 2002). Equality and inequality between men and women is based on the following factors (Acker 2002): 'prestige in the community, style of life, privileges and opportunities, association with social groups, income, education, occupation and power'. These criteria define both the individual's and societal interactions which can be relevant in disaster situations and will have an influence on the vulnerability of a given population segment. Traditions will have a strong influence here.

Gender differences in South Africa are pronounced and there is currently an ongoing debate about the roles of men, women and gender in the South African society (MacLeod 2007; Morrell 2007). Data and research show that a high proportion of young men are involved in sexual violence (Jewkes et al. 2006). Gender aspects of domestic violence have been analysed and results indicate that if traditional male roles are under threat then the level of violence increases (Hautzinger 2003). Results on gender aspects of vulnerable groups in Africa vary. Silberschmidt $(1992,2001)$ found that rates of alcoholism and promiscuity amongst men tend to increase in situations of economic vulnerability. This is partially caused by the perceived failure of men as providers for the household (Silberschmidt 1992, 2001). Hunter (2004) showed self-preservation to be an important component of the male gender perception in South Africa.

Historically, gender roles have been in a state of flux in the African continent (Oyewumi 1997) and the relevant research efforts have been complicated by the multicultural nature of society (Morrell 2007). Women, traditionally, have looked after the household in South Africa (Ngubane 2010). This in turn provided a foundation for the men to be economically active outside the household (Walby 2002). Unless there is an additional income from subsistence agriculture, craft production, domestic work, this arrangement can increase disaster vulnerability for the women. This is the result of financial dependence on income derived from money sent home by the men (Walby 2002). Here, patriarchal social structure will have strong disaster risk reduction (DRR) implications. Besides the traditional work divisions, economic inequality originates from the following (Hartman 2002): 'the exclusionary policies of male unions, the financial responsibility of men for their families, the willingness of females to accept lower wages than their male counterparts; and finally lack of relevant skills in the female segment of the population'. In South Africa, the gender inequality is likely to be a result of the combination of traditions, the apartheid era policies and the current social challenges.

Societal perceptions about gender and sex influence the vulnerability and resilience of men and women during disasters (United Nations Development Programme 2010). They also determine the efficacy of DRR strategies (United Nations 2008), making the gender and sex implications an important part of DRM. Facts from this section clearly point to the challenging nature of understanding and research on the subject of gender in South Africa. It is nonetheless important and should receive more research attention. Taking the theoretical pitfalls into account, only a preliminary assessment can be performed at present. However, this subject requires urgent focus to make fundamental arrangements in the DRM context. From this point of view, the most valuable information would come from the derivation of parameters within which one could quantify the gender inequalities and risks of the South African population. It is thus the aim of the current article to conduct such an assessment for vulnerability and disaster-related fatalities in South Africa.

\section{Methodology}

The United Nation figures showed that up to $42.9 \%$ of the South African population lived on less than \$2 per day between 2000 and 2006 (United Nations Development Programme 2008). Black African women were particularly 
under income strain as the majority of them were working in the informal sector (United Nations Development Programme 2008). Up to one million poor households were found in the rural areas and were headed by a female (Amsterdam Institute for Advanced Labour Studies 2009). Data from 2002 show that up to 840000 Black and Coloured women and around 180000 men were economically vulnerable due to employment in the informal sector where they performed low-skilled labour such as cooking, domestic work, gardening and child-minding (Hertz 2004). The minimum wage and unemployment insurance regulations were inadequately enforced (Hertz 2004). These figures indicate vastly different vulnerability of the genders in the South African population. This in turn further strengthens the case for assessment of the vulnerability and disaster-related fatality trends in South Africa.

To facilitate the relevant analyses, data were collected from several sources and used to evaluate the gender trends in vulnerability and disaster-related fatalities in South Africa. Vulnerability is a function of multiple parameters (as discussed in the Introduction), so a relevant assessment will comprise evaluation of inequalities with respect to the health status of the population, access to healthcare, education background and inequality amongst genders, economic situation and inequality in South Africa. Housing will also be touched upon and the temporal trends in the inequality indices will be evaluated where possible in an attempt to understand the medium- and long-term development trends in the vulnerability of the South African population. Besides vulnerability, gender trends and inequality with respect to fatalities will be studied. The reason for this is that trends in this parameter form the basis of the DRM and planning (Luyt et al. 2011). There are also significant knock-on effects from disaster-related fatalities which need to be understood.

\section{Vulnerability assessment}

First of all, the gender inequality indices were calculated with respect to the health status of the population. The life expectancy at birth for men and women is an overall measure of health conditions in a given country (United Nations 2012). Any gender differences with regard to this parameter can thus provide an indication about the health and/or disease burden differences between men and women in South Africa. Such information in turn contributes to the understanding of gender vulnerability disparities. It facilitates efficient and gender-specific medical assistance and response in DRM planning. The relevant data on life expectancy for men and women was obtained from the United Nations reports on the status of women globally (UNRW 1995, 2000, 2005, 2010). The life-expectancy-at-birth inequality index (LEABI) was calculated based on that data according to Equation (1).

LEABI $=\frac{\text { Age }(\text { woman })}{\text { Age }(\text { men })}$

In Equation (1), Age (women) is the average life expectancy at birth for women in South Africa (in years), whilst Age (men) stands for the average life expectancy at birth for men in the country (in years). The LEABI criterion is dimensionless. The Maternal Mortality Rate 'reflects the extent to which women are exposed to risk through fertility' (Dorrington \& Bradshaw 2011) and is a critical measure of the access to healthcare by the country's women (World Health Organisation [WHO] 2012a). If women and/or mothers are the primary caregivers, then their access to healthcare will be vital to the disaster recovery of the whole family. The maternal mortality rates were extracted from the United Nations Reports on the Status of Women globally (UNRW 1995-2010) and from the Health Systems Trust data (HST 2011). Trends in the maternal mortality rates with the country's development were also analysed (see Figure 2 for details).

Recent statistical data has shown that female-headed households are larger in size and are also more prone to hunger (Statistics South Africa [SSA] 2010). If the nutritional standing of females as primary breadwinners is to be compromised then this decreases their ability to provide for the family in question. Under such circumstances, more dependents will become vulnerable than if a male-headed household were to be considered. At the same time, a significant proportion of the South African female-headed households are dependent on the informal sector for income and access to healthcare. Given these facts, the LEABI and the access to healthcare, linked to the maternal mortality rate, are critical in the context of DRM in South Africa. This reasoning therefore justifies the selection of the criteria to assess the health of the population and the related inequality in South Africa.

In a disaster situation, the economic background of the population will dictate their preparedness to evacuate the affected area (Nigg et al. 2006) and also controls the recovery of livelihoods (Norris et al. 2008). Analysis of genderbased inequalities can thus provide information about the increasing or decreasing disaster vulnerability for men and women. To evaluate the relevant trends, the dimensionless unemployment inequality index (UEI) was calculated using Equation (2), based on the available and official South African statistics for 2008 until 2011 (SSA 2012).

$\mathrm{UEI}=\frac{\text { Unemployment Rate }(\text { woman })}{\text { Unemployment Rate }(\mathrm{men})}$

[Eqn 2]

In Equation (2), Unemployment Rate (women) is the average unemployment rate for women in South Africa (\% of the female population in the productive age range of 15-64), whilst Unemployment Rate (men) stands for the average unemployment rate for their male counterparts in South Africa ( $\%$ of the male population in the productive age range of 15-64).

Educational status of the population was evaluated using the literacy rates in men and women; and the ratio of the enrolment rates at primary and secondary levels. This is based on the fact that on average only $9.8 \%$ of the population who are older than 20 years took up tertiary studies in South Africa between 2002 and 2010 (SSA 2011a). Only limited gender data was available, namely the literacy rates 
breakdown for men and women in the calendar years 2007 and 2011; and enrolment for data at both education levels for 2009 (UNRW 1995-2010). The respective inequality indices were estimated using Equations (3) and (4).

LRII $=\frac{\text { Literacy Rate }(\text { woman })}{\text { Literacy Rate }(\text { men })}$

$\mathrm{EII}=\frac{\text { Enrolment Rate }(\text { woman })}{\text { Enrolment Rate }(\mathrm{men})}$

In Equation (3), Literacy Rate (women) is the average literacy rate for women in South Africa (expressed in \% of the total female population who can read), whilst Literacy Rate (men) is the average literacy rate for men in the country (expressed in \% of the total male population who can read). At the same time, LRII stands for the literacy inequality index (dimensionless). In Equation (4), Enrolment Rate (women) is the average enrolment rate for females in the primary and/ or secondary education institutions across South Africa (\%), whilst Enrolment Rate (men) is the average enrolment rate for males in the primary and/or secondary education institutions across South Africa (\%). In the same equation, EII stands for the enrolment inequality index (dimensionless).

Awareness and prevention campaigns about disaster risks and relief procedures decrease the damages and casualty numbers during disasters (International Society of Red Cross and Red Crescent Societies 2011). Relevant materials have been developed by the National Disaster Management Centre (NDMC) and are available to the population. Educational status of the population will be determined by factors such as the highest qualification attained and level of education completed. It will also depend on literacy rates (International Society of Red Cross and Red Crescent Societies 2011). Efficiency of awareness campaigns and the population's ability to extract relevant information from the resources provided will play an important role in DRM. Based on these criteria, the LRII and EII indices are justified in order to characterise the disaster inequalities which might exist in South Africa. A relationship has been reported between the developmental stage of a given country and the gender inequality in that country, as it is determined by the economic drivers of the country (Kuznets 1955). To assess these trends for South Africa, the maternal mortality rates and values calculated according to Equations (1-4) were evaluated as a function of the human development index (HDI) (UNHDI 2012).

\section{Gender aspects of fatalities}

Effects of disasters can be evaluated in terms of material and infrastructural losses, injuries and fatalities, and other parameters. Some of the relevant information is available through the NDMC website, but access to the majority of the relevant databases is often restricted to government officials. Another source of information is the official statistical data from Statistics South Africa. An embargo period is generally placed on it though, so up to two years can pass before the relevant data is available in the public domain. Under these circumstances, only a few datasets can be used to assess the gender-related effects of disasters in South Africa. Examples of such datasets include deaths from unnatural and/or nonnatural causes where the sex and/or gender breakdown is available for the periods 1997-2004 and for 2009 (SSA 2006, 2011b). These will therefore be used, together with additional data, to perform a preliminary assessment of the gender aspects of disaster-linked fatalities in South Africa.

The terms unnatural and non-natural will be deemed synonymous from this point on, as their subcategories are comparable. The 1997-2004 unnatural deaths consist of the following subcategories: 'death by firearm, death by knife (stabbing), poisoning, transport and undetermined intent and/or unspecified event' (SSA 2006). The dataset for 2009 contains subtypes of non-natural deaths, namely:

[o]ther external causes of accidental injury, event of undetermined intent, transport accidents, assault, smoke inhalation, exposure to smoke, fire and flames; accidental drowning and submersion; accidental poisoning by and exposure to noxious substances; exposure to forces of nature and to electric current, radiation and extreme ambient air temperature and pressure, complications of medical and surgical care, intentional self-harm and sequelae of external causes of morbidity and mortality. (SSA 2011b)

During disaster situations, death of human beings can occur due to any of the following reasons: drowning, smoke inhalation, burns, assault in the aftermath of the disaster, radiation exposure and crushing under falling debris or damaged buildings (Kelman 2012). Certain subcategories must therefore be excluded from the unnatural deaths data from South Africa, so that the results reflect only the gender aspects of the disaster-related fatalities.

The first subtype to be excluded is the deaths from 'undetermined intent/unspecified event' where the cause of death can't be established (SSA 2006, 2011b). If such values were to be included in the relevant calculations in this article, then the conclusions drawn would not necessarily reflect the outcomes of disasters. Patient complications in medical and surgical care can occur in disaster victims. However, human action which can be unrelated to the disaster itself will ultimately lead to the patient's death. Iatrogenesis is possible whether the DRM systems function properly or even if no disaster has taken place. Therefore, this type of unnatural cause of death will be subtracted from the total disaster nonnatural death count. The relevant values were missing from the 1997-2004 dataset. Comparable estimates for males and females were derived for the year 2000 (Bradshaw et al. 2003). These values are assumed to be representative for the entire 1997-2004 period and will be subtracted from the particular disaster-related unnatural deaths (see below).

The subcategory of 'sequelae of external causes of morbidity and mortality' includes fatalities which can be related to transport accidents and intentional self-harm, amongst others, but the death generally occurs around one year after the causal event (WHO 2012b). At the same time, other factors besides disasters significantly contribute to this type 
of fatalities. Deaths assigned to this cause will therefore be subtracted from the total number of unnatural deaths in further considerations of disaster-related fatalities. Mortality and morbidity from intentional self-harm is mainly related to political statements, societal pressure and mental health problems of people committing it (Laloë 2004). Exclusion of this cause of death from the disaster-related fatality considerations is thus necessary and will be performed in the data analysis.

Transport accidents have been studied extensively in South Africa by such authors as Lerer and Matzopoulos (1996) and Meel (2008). Other types of disasters have not been studied to the same extent. Transport death rates will therefore be subtracted from the unnatural death rates, focusing the analysis on non-transport disasters. Assaults can occur as a consequence of disasters (Kolbe et al. 2010) or in the aftermath of disasters (Widgren 1995). Such deaths are violent in nature and significant gender differences have been reported (Kolbe et al. 2010). The relevance of these factors to disasters in South Africa originates from the high exposure of the population to traumatic events (Williams et al. 2007), and as a result these types of deaths will be included amongst the disaster fatalities.

Deaths from smoke inhalation and drowning are related to fires and floods, so they will be included in the disaster-related deaths in South Africa (SSA 2011b). Mining constitutes a significant part of South Africa's GDP (SSA 2009a). Exposure of South African citizens to radiation has been reported as a consequence of consumption of drinking water in the mining-intensive areas (North-West Provincial Government 2002). Inhalation of toxic gases can also occur in the mines, according to the Mine Health and Safety Act 29 of 1996 (South Africa 1996). Therefore, the unnatural deaths from radiation exposure and poisoning will be relevant to disasters in the South Africa; and must be included in the disaster-related fatalities. Ambient temperatures have been shown to vary significantly around South Africa (South African Weather Service 2010), so exposure to extreme temperatures and atmospheric pressure must be taken into consideration with regard to the disaster-related fatalities in South Africa. The same reasoning and inclusion applies to the remainder of the unnatural causes of death in South Africa (SSA 2011b).

\section{Fatality calculations}

Data for unnatural deaths are reported as the number of deaths per 100000 citizens of South Africa, meaning that the total death rates and values are broken down according to age and gender (SSA 2006, 2011b). Between 1997 and 2004, the average of all death cases captured through death notifications was equal to $84.7 \%$ for the age group $15-64$ years of age (SSA 2006). Only 51\% of all deaths were collated for the $0-14$ age group and $104.7 \%$ of all death causes were captured for the over-65 age group (SSA 2006). Over-reporting of the number of deaths makes it difficult to determine which cause of death the available data is valid for and which not. At the same time, the highly incomplete dataset for the $0-14$ years of age group will severely invalidate any conclusions being drawn therefrom. More than $100 \%$ of unnatural deaths were reported in the above-65 age group, but data for this age group is only of limited policy value (SSA 2006). Results for the 15-64 age group provides the most valuable policy input (SSA 2006). Further analyses will thus be focused on this age group and the conclusions will be interpreted in the context of the quality of the source data.

Based on the above discussion, the disaster-related death rates (DRDR) were calculated for men and women separately using Equation (5).

$$
\begin{aligned}
& \text { DRDR }=\text { TUDR }- \text { TDR }- \text { MEDR }- \text { UDDR }- \text { SEJDR } \\
& - \text { PSHDR }
\end{aligned}
$$

Here TUDR is the total death rate from unnatural causes reported in a given calendar year, whilst TDR is the transport death rates for the same. The MEDR values represent the death rates from medical and/or surgical errors. The term UDDR indicates the undetermined cause and/or intent death rate. At the same time, SEJDR is the death rate from the sequelae of external injuries and PSHDR is the death due to intentional self-harm. All terms in Equation (5) were obtained separately for the male and female parts of the population. The unit of all death rates is the number of deaths per 100000 citizens (Bradshaw et al. 2003; SSA 2006, 2011b). Publications from SSA (SSA 2006, 2009b, 2011b) were the source for the following data: TUDR, TDR and UDDR for 1997-2004 and 2009, and MEDR for 2009. The SEJDR, MEDR and PSHDR values for the time period from 1997-2004 were derived from the estimates of Bradshaw et al. (2003).

The TUDR values were reported for individual age groups for men and women, separately (SSA 2006, 2009c, 2011b). Thereafter, the respective TUDR values were converted into the overall death rates for the 15-64 age group by using Equation (6).

$\mathrm{TUDR}=\sum_{\mathrm{i}=1}^{\mathrm{k}} \omega_{\mathrm{i}} \times \mathrm{TUDR}_{\mathrm{i}}$

[Eqn 6]

In Equation (6), TUDR ${ }_{i}$ is the respective unnatural death rate for the given age group and gender and/or sex (number of deaths per 100000 citizens of South Africa). The symbol $\omega_{\mathrm{i}}$ represents the weighting factor of that particular age group of the male or female part of the population (dimensionless). The values of $\omega_{\mathrm{i}}$ were calculated according to Equation (7).

$\omega_{\mathrm{i}}=\frac{\text { Number (given age group) }}{\text { Number (total gender) } \times \Phi(15-64)}$

[Eqn 7]

The term Number (given age group) in Equation (7) is the total number of males or females of a given age group in South Africa in a particular year (number of people). In the same equation, Number (total gender) is the total number of males or females in the South African population in a given year (number of people). Lastly, $\Phi(15-64)$ stands for the fraction of the total male or female population which is accounted for the by the 15-64 age group (dimensionless). The official population estimates were used to indicate the 
total population of South Africa in 2003 (SSA 2003), 2004 (SSA 2004) and 2009 (SSA 2009c). The respective values for 2003 and 2004 were averaged; and assumed to be equal to the mean $\omega_{\mathrm{i}}$ values for the 1997-2004 period. The population estimate for 2009 for used for that calendar year only. The respective TUDR and $\omega_{\mathrm{i}}$ values are summarised in Tables 1-3.

For the 1997-2004 period, the unspecified event or undetermined intent categories were reported only as percentages of TUDR in a particular calendar year (SSA 2006). The relevant fractions $\Pi(15-64)$ were equal to the following values: 0.79 in 1997, 0.66 in 1998, 0.40 in 1999, 0.34 in 2000, 0.35 in 2001, 0.38 in 2002 and 0.37 in both 2003 and 2004. Thus the UDDR were calculated as percentages of the TUDR using Equation (8).

UDDR $(1997-2004)=\Pi(15-64) \times$ TUDR

[Eqn 8]

In Equation (8), UDDR and TUDR have the same meaning and units as in Equations (5) and (6). The UDDR values for 2009 were calculated from the death counts assigned to the cause of undetermined intent (Tables 1 and 2). The TDR values were calculated using the SSA data for death due to traffic accidents for years between 2001 and 2004; and in 2009, according to Equation (9).
$\mathrm{TDR}=\frac{100000 \times \text { Gender deaths }}{\text { Total population (South Africa) }}$

[Eqn 9]

In Equation (9), Gender deaths are the total number of deaths in South Africa in the given calendar year where the cause was a traffic accident for males or females (number of deaths) (SSA 2009b). At the same time, Total population is the midyear estimate of the total South African population in a given calendar year (SSA 2009b, 2009c). The coefficient of 100000 converts the death rates into the units of number per 100000 inhabitants of South Africa (SSA 2009b). The calculated values are outlined in Table 4.

The death rates between 2001 and 2004 were averaged to give the mean values of 6.0 per 100000 inhabitants for men and to 1.9 per 100000 inhabitants for women. These values were assumed to be representative of TDR for the entire 1997-2004 period. The TDR value for 2009 was equal to 7.3 per 100000 inhabitants for men and to 2.1 per 100000 inhabitants for women. All values of MEDR, SEJDR and PSHDR for 19972004 and 2009, along with the UDDR values, were calculated according to Equation (10) and using the data of Bradshaw et al. (2003) and Statistics South Africa (SSA 2011b).

GDR $=\frac{100000 \times \text { Gender deaths }}{\text { Total population (South Africa) }}$

[Eqn 10]

TABLE 1: The male TUDR values reported between 1997 and 2004

\begin{tabular}{|c|c|c|c|c|c|c|c|c|c|}
\hline \multirow[t]{2}{*}{ Age group } & \multirow[t]{2}{*}{$\omega_{i}$} & \multicolumn{8}{|c|}{ Deaths per 100000 citizens } \\
\hline & & 1997 TUDR & 1998 TUDR & 1999 TUDR & 2000 TUDR & 2001 TUDR & 2002 TUDR & 2003 TUDR & 2004 TUDR \\
\hline $15-19$ & 0.178 & 161 & 151 & 153 & 149 & 146 & 142 & 140 & 136 \\
\hline $20-24$ & 0.158 & 271 & 268 & 265 & 279 & 290 & 302 & 302 & 307 \\
\hline $25-29$ & 0.146 & 356 & 349 & 317 & 311 & 318 & 319 & 317 & 316 \\
\hline $30-34$ & 0.122 & 366 & 373 & 350 & 363 & 386 & 377 & 384 & 376 \\
\hline $35-39$ & 0.101 & 336 & 352 & 353 & 346 & 368 & 371 & 352 & 359 \\
\hline $40-44$ & 0.089 & 324 & 335 & 337 & 335 & 346 & 357 & 360 & 350 \\
\hline $45-49$ & 0.073 & 316 & 315 & 314 & 307 & 325 & 310 & 311 & 305 \\
\hline $50-54$ & 0.059 & 319 & 303 & 288 & 283 & 287 & 281 & 286 & 278 \\
\hline $55-59$ & 0.042 & 301 & 286 & 278 & 265 & 243 & 251 & 245 & 234 \\
\hline $60-64$ & 0.033 & 270 & 254 & 246 & 227 & 241 & 259 & 236 & 238 \\
\hline UDDR & - & 232.3 & 192.8 & 113.3 & 96.1 & 102.2 & 111.3 & 107.6 & 106.7 \\
\hline Overall male TUDR & - & 294.0 & 292.1 & 283.2 & 282.6 & 291.9 & 292.9 & 290.8 & 288.3 \\
\hline
\end{tabular}

Source: The TUDR values were extracted from the South African statistical publications (SSA 2006, 2009c, 2011b) and calculated according to Equation (6)

TUDR, total death rate from unnatural causes.

TABLE 2: The female TUDR values reported between 1997 and 2004.

\begin{tabular}{|c|c|c|c|c|c|c|c|c|c|}
\hline \multirow[t]{2}{*}{ Age group } & \multirow[t]{2}{*}{$\omega_{\mathrm{i}}$} & \multicolumn{8}{|c|}{ Deaths per 100000 citizens } \\
\hline & & 1997 TUDR & 1998 TUDR & 1999 TUDR & 2000 TUDR & 2001 TUDR & 2002 TUDR & 2003 TUDR & 2004 TUDR \\
\hline 15-19 & 0.168 & 53 & 47 & 50 & 46 & 44 & 40 & 39 & 38 \\
\hline $20-24$ & 0.150 & 75 & 75 & 76 & 72 & 74 & 86 & 92 & 91 \\
\hline $25-29$ & 0.140 & 79 & 82 & 84 & 78 & 79 & 80 & 89 & 86 \\
\hline $30-34$ & 0.120 & 84 & 85 & 84 & 80 & 81 & 84 & 82 & 85 \\
\hline $35-39$ & 0.104 & 89 & 90 & 90 & 77 & 74 & 79 & 75 & 82 \\
\hline $40-44$ & 0.092 & 91 & 87 & 78 & 75 & 71 & 73 & 73 & 72 \\
\hline $45-49$ & 0.078 & 94 & 84 & 87 & 73 & 69 & 71 & 64 & 69 \\
\hline $50-54$ & 0.062 & 107 & 90 & 90 & 73 & 66 & 70 & 68 & 70 \\
\hline 55-59 & 0.046 & 106 & 96 & 95 & 83 & 77 & 73 & 69 & 73 \\
\hline $60-64$ & 0.040 & 106 & 100 & 89 & 92 & 89 & 84 & 85 & 82 \\
\hline UDDR & - & 52.9 & 42.6 & 26.0 & 20.0 & 20.2 & 22.8 & 22.4 & 22.6 \\
\hline Overall female TUDR & - & 66.9 & 64.5 & 64.6 & 58.8 & 57.6 & 59.9 & 60.4 & 61.1 \\
\hline
\end{tabular}

Source: The TUDR values were extracted from the South African statistical publications (SSA 2006, 2009c, 2011b) and calculated according to Equation (6)

TUDR, total death rate from unnatural causes. 
TABLE 3: The male and female TUDR values for the 2009 calendar year.

\begin{tabular}{lllcc}
\hline Age group & $\omega_{\mathrm{i}}$ (men) & $\omega_{\mathrm{i}}$ (women) & \multicolumn{2}{c}{ Deaths per 100 000 citizens } \\
\cline { 3 - 5 } & & & Male TUDR & Female TUDR \\
\hline $15-49$ & 0.962 & 0.956 & 57.7 & 12.5 \\
$50-64$ & 0.038 & 0.044 & 8.9 & 2.8 \\
\hline Overall male TUDR & - & - & $\mathbf{5 5 . 8}$ & $\mathbf{1 2 . 0}$ \\
\hline
\end{tabular}

Source: The TUDR values and $\omega_{\mathrm{i}}$ (men; women) were extracted from the South African statistical publications (SSA 2009c, 2011) and calculated using Equations (6) and (7)

statistical publications (SSA 2009c, 2011) and calc
TUDR, total death rate from unnatural causes.

In Equation (10), GDR stands for the death rate from a given cause for males or females (number of deaths per 100000 citizens of South Africa). The term, Gender deaths, represents the total number of deaths in South Africa in a particular year resulting from a given cause of death for males or females (number of deaths) (SSA 2009b). Lastly, Total population is the mid-year population estimate for a given calendar year (SSA 2006, 2009b, 2009c). The coefficient of 100000 converts the death rates into the units of number per 100000 inhabitants of South Africa (SSA 2009b). The calculated values can be found outlined in Table 5 .

The DRDR values for male and female parts of the South African population were then calculated using the data from Tables 1, 2, 3, 4 and 5 and Equation (5). These were subsequently used to derive the disaster-related death inequality index (DII) which is defined in Equation (11).

$\mathrm{DII}=\frac{\mathrm{DRDR}(\text { women })}{\operatorname{DRDR}(\text { men })}$

In Equation (11), DRDR (women) is the female death rate from disasters in South Africa (number of female deaths per 100000 inhabitants). At the same time, DRDR (men) is the male disaster-related death rate for men in the country (number of male deaths per 100000 inhabitants). The calculation results are shown in Table 6.

\section{Results and discussion Vulnerability assessment}

The inequality indices for health and economic status describe the disparity between men and women with respect to a given parameter. If there is no gender disparity then the particular inequality index will be equal to 1.0. If women are more vulnerable with respect to a given parameter than men, the particular inequality index will be higher than 1.0, and if men are more vulnerable than women, the inequality index in question will be lower than 1.0. The health status inequality index is plotted in Figure 1. Between 1980 and 2011, the life expectancy at birth ranged from 51 to 66 years for women and from 47 to 60 for men (UNRW 1995-2010). Minimum life expectancies of 53 years for men and 54 years for women were reported in 2011. The LEABI values did not follow any systematic trend with the HDI, that is, with the level of South Africa's human development. The mean LEABI value was equal to 1.084 , whilst the average HDI value stood at 0.610 (see Figure 1 for details).

South Africa has therefore reached a medium level of human development, and the life expectancy of women is on average about $10 \%$ higher than for men. However, the gender differences seem to decrease with time, as the LEABI minimum of 1.019 was reached in 2011. Thus the health status of male and female parts of the population has likely been comparable between 1980 and 2011, indicating a comparable level of the health disaster vulnerability for both genders in South Africa. The overall health vulnerability of the population increased for the same time period, as the life expectancy at birth has decreased from 1980 until 2011.

According to data in Figure 2, the maternal mortality rate reached a minimum value of 54 between 2000 and 2005; and

TABLE 4: The gender-segregated TDR values.

\begin{tabular}{llllll}
\hline Year & $\begin{array}{l}\text { Male deaths due to } \\
\text { traffic accidents }\end{array}$ & $\begin{array}{l}\text { Female deaths due to } \\
\text { traffic accidents }\end{array}$ & Total Population & \multicolumn{2}{l}{$\begin{array}{l}\text { Male TDR per 100 000 } \\
\text { citizens }\end{array}$} \\
\hline 2001 & 2751 & 828 & 44909738 & 6.1 \\
2002 & 2220 & 726 & 45533292 & 4.9 & 1.8 \\
2003 & 2809 & 886 & 46116494 & 6.1 & 1.6 \\
2004 & 3239 & 1006 & 46664771 & 6.9 & 2.9 \\
2009 & 3607 & 1035 & 49320500 & 2.3 & \\
\hline
\end{tabular}

Source: The TDR values were extracted from the South African statistical publications (SSA 2006, 2009b) and calculated according to Equation (9) TDR, transport death rates.

TABLE 5: The average GDR values for the 1997-2004 period as calculated using Equation 5.

\begin{tabular}{|c|c|c|c|c|c|}
\hline Parameter & $\begin{array}{l}\text { Male deaths } \\
\text { (number of deaths) }\end{array}$ & $\begin{array}{l}\text { Female deaths } \\
\text { (number of deaths) }\end{array}$ & Total Population & $\begin{array}{l}\text { Male deaths rate per } \\
100000 \text { citizens }\end{array}$ & $\begin{array}{l}\text { Female deaths rate per } \\
100000 \text { citizens }\end{array}$ \\
\hline MEDR 1997-2004 & $245^{a}$ & $247^{a}$ & $46508215^{b}$ & 0.5 & 0.5 \\
\hline PSHDR 1997-2004 & $4502^{\mathrm{a}}$ & $1386^{\mathrm{a}}$ & $46508215^{b}$ & 9.7 & 3.0 \\
\hline SEJDR 1997-2004 & $400^{c}$ & $115^{c}$ & $46508215^{b}$ & 0.9 & 0.2 \\
\hline MEDR 2009 & 130 & 118 & 49320500 & 0.3 & 0.2 \\
\hline UDDR 2009 & 4628 & 1126 & 49320500 & 9.4 & 2.3 \\
\hline PSHDR 2009 & 262 & 81 & 49320500 & 0.5 & 0.2 \\
\hline SEJDR 2009 & 15 & 6 & 49320500 & 0.03 & 0.01 \\
\hline
\end{tabular}

Source: Data were extracted from Bradshaw et al. (2003) and SSA (2003, 2004)

, Values were obtained from Appendix D in Bradshaw et al. (2003).

b, Average population as estimated from the 2003 and 2004 mid-year estimates of the South African population (SSA 2003, 2004).

c', Estimated from the deaths due to other unintentional injuries from Appendix D in Bradshaw et al. (2003). 
the maximum of 325 was reached in 2008. As with LEABI, no systematic trend was observed between the maternal mortality rates and the HDI (see Figure 2). The United Nations and the HST data for the maternal mortality rates are lower than or comparable to other literature sources (Hogan et al. 2010). The maternal mortality rates in the southern part of sub-Saharan Africa have been reported to range from 121 to 1021 death rates per 100000 reproductive years between 1980 and 2008 (Hogan et al. 2010). Thus the South African statistics are comparable to or lower than the maternal mortality rates in the surrounding countries. South Africa is a member of the G20 and has, on average, reached a higher level of human development than the neighbouring countries (UNHDI 2012). This is likely to lead to higher spending on healthcare in South Africa in comparison to other countries in the region, providing an explanation for the observed maternal mortality trends.

Between 1997 and 2004, the statistical data point to a significant decrease in the survival of the female portion aged 15-45 (SSA 2006). This is in agreement with the increase in the maternal mortality rate, as the maximum value was recorded in 2008. This data indicates a decreasing trend in women's access to quality healthcare and thus increasing disaster vulnerability with respect to health status. The UEI as a function of the HDI is depicted in Figure 3. The UEI ranged from a minimum of 1.163 observed in 2009 to the maximum of 1.330 in 2008. Based on these results, women are $16.3 \%$ $33 \%$ more likely to be unemployed than men in South Africa. Thus the female part of the population will experience a higher level of economic vulnerability compared to the male one in South Africa.

In $2007,87 \%$ of women and $91 \%$ of men were literate in South Africa. These figures increased to $98 \%$ for women and $97 \%$ for men in 2011. As a result, the LRI values are equal to 0.956 in 2007 and 1.013 in 2011. The literacy rate for women and men has increased between 2007 and 2011, and the literacy rates for the two genders are comparable. Therefore, neither of the two genders is likely to experience increased relative vulnerability in this regard, as the EII for 2009 was equal to 0.960 and 1.040 at the primary and secondary levels.

The HDI values for South Africa varied by $9.5 \%$ between 1980 and 2011, and they fluctuated with time (UNHDI 2012). The G20 group of the most important economies in the world has experienced a change in the HDI of between $8.5 \%$ and $19 \%$ between 1980 and 2011. With time, the HDI has increased and then levelled off for the G20 countries (UNHDI 2012). South Africa is a member of the G20 group, but it experienced a fluctuating temporal trend in HDI with time between 1980 and 2011. This applies to the whole time interval, even over shorter periods such as 2008-2011. South Africa does not, therefore, follow a Kuznets model of the U-shaped dependence of gender inequality on the level of human development (Kuznets 1955). This observation explains the trends in Figures 1-3 and is in line with the majority of the South African GDP not originating from agriculture.

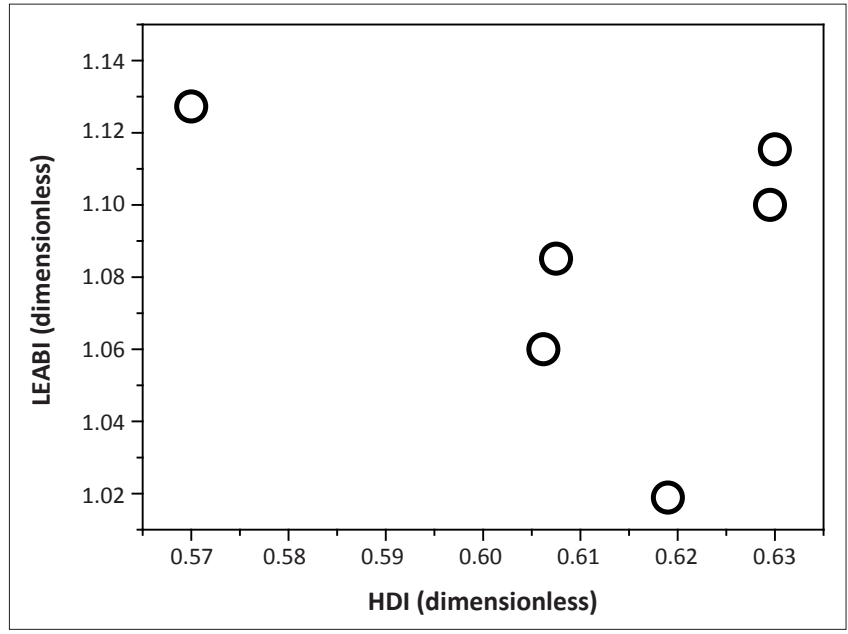

Source: Developed from data for study

Note: LEABI as a function of the human development index (HDI) is shown for South Africa between 1980 and 2011. The respective LEABI values were calculated according to Equation (1). Data for 1980 until 2010 are presented as arithmetic averages for the respective fiveyear increments, whilst the value for 2011 only represents an individual year.

FIGURE 1: The life-expectancy-at-birth inequality index (LEABI) versus the Human Development Index (HDI).

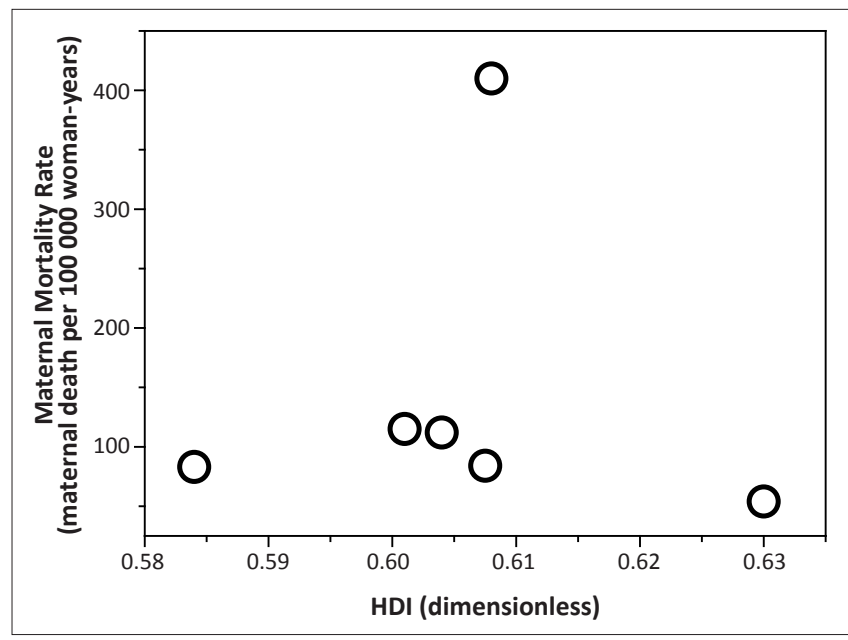

Source: Developed from data for study

Note: The maternal mortality rate is shown as a function of the human development index (HDI) for South Africa and the time period from 1980 until 2008. The HDI data for 1980 until 2005 are presented as arithmetic averages for the respective five-year periods, whilst the values for 2006-2008 only represent individual years. The 2008 Maternal Mortality Rate is an average of the United Nations values and the Health Systems Trust values.

FIGURE 2: Maternal mortality rate versus the Human Development Index (HDI).

\section{Gender aspects of the disaster fatalities}

The respective DRDR values are summarised in Table 6.

The calculated death rates from disasters ranged from 38.3 to 172.6 for men; and from 7.2 to 33.2 for women. The minimum values were observed for both genders in 2009, whilst the maximum values were observed in 2001 for men and in 2000 for women. The DII values fluctuated during the period examined in this article, but no systematic trend was observed. The average DII value was equal to 0.20 , indicating that the male portion of the population is five times more vulnerable to disaster fatalities than its female counterpart.

As early as 2009 there has been a call from different stakeholders for the involvement of women and children 


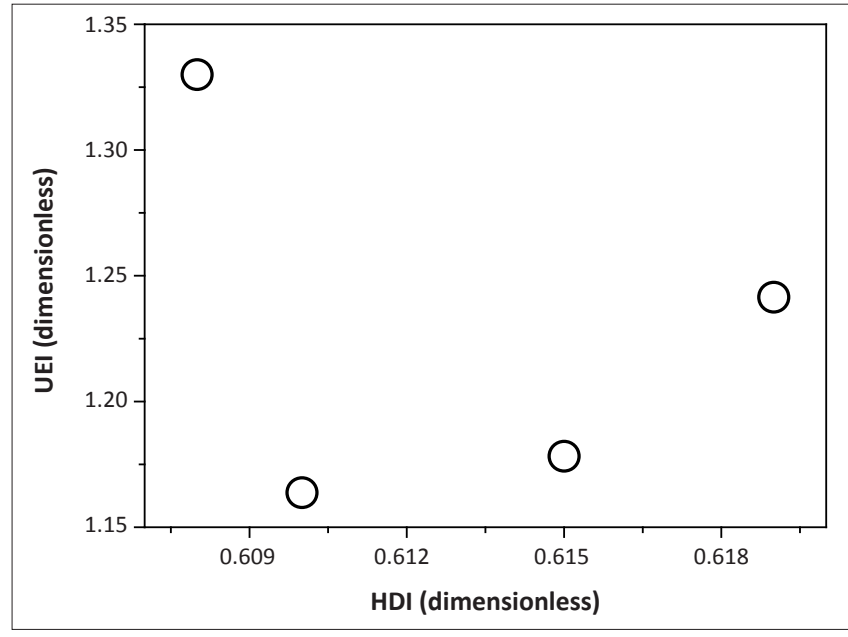

Source: Developed from data for study

Note: The unemployment inequality index (UEI) is plotted as a function of the human development index (HDI) for South Africa and the time period from 2008-2011. The respective UEI values were calculated according to Equation (2) and are averaged out over the relevant quarters of 2008-2011.

FIGURE 3: The unemployment inequality index (UEI) vs. the Human Development Index (HDI).

TABLE 6: Values of DRDRs and DII in South Africa between 1997 and 2004; and for 2009.

\begin{tabular}{lccc}
\hline Calendar year & \multicolumn{2}{c}{ DRDR per $\mathbf{1 0 0}$ 000 citizens } & \multirow{2}{c}{$\begin{array}{c}\text { DII } \\
\text { Dimensionless }\end{array}$} \\
\cline { 2 - 3 } & Males & Females & \\
\hline 1997 & 44.6 & 8.4 & 0.19 \\
1998 & 82.2 & 16.3 & 0.20 \\
1999 & 152.8 & 33.0 & 0.22 \\
2000 & 169.4 & 33.2 & 0.20 \\
2001 & 172.6 & 31.8 & 0.18 \\
2002 & 164.5 & 31.5 & 0.19 \\
2003 & 166.1 & 32.4 & 0.20 \\
2004 & 164.5 & 32.9 & 0.20 \\
2009 & 38.3 & 7.2 & 0.19 \\
\hline
\end{tabular}

Source: Data was calculated using Equations (5) and (11)

DRDR, disaster-related death rates; DII, death inequality index.

(vulnerable groups) in DRM planning, as well as in accounting for gender considerations in the same context (NDMC 2009). Equality has been achieved at the employee level of the Provincial Disaster Management Centres where in 2006 the number of male employees equalled the number of female ones (NDMC 2006-2007). This is in line with the gender-equality strategy for the public service as adopted at the 6th Pan African Conference of Ministers of Public Administration (Service Delivery Review 2009). Findings from this article indicate that such efforts should further be strengthened with respect to economic vulnerability and women's access to quality healthcare. Fatality calculations and relative risks derived in this article must be approached and used with caution and they are based on limited data and statistical estimates. However, the calculation results do point to the fact that men are five times more likely to die in non-transport disaster in South Africa.

DRR should therefore focus on the male gender in South Africa in more detail. Strategies should include awareness campaigns about disaster-related risks in the individual provinces in South Africa. The respective materials have already been developed by the NDMC, but translation into languages besides English will be needed. The analysis used in this article demonstrates two aspects of data on disasters in South Africa. Firstly, public domain databases can be used to derive the baseline data for DRM in the absence of specialised datasets. At the same time, the quality of data available in said databases varies between sources and calendar years. Reserves also exist in the quality of data capturing (see rates of death notifications captured for the 1997-2004 time period). Dedicated databases of the NDMC and national government should be made available to the public to facilitate more research into the gender aspects of DRM in South Africa. To take the interconnectivity of the genders with respect to disaster vulnerability, policy drafting and implementation should be directed towards the insurance scheme programmes targeted at the most vulnerable segments of the population, such as parametric insurance (Arnold 2008).

\section{Conclusions}

The results of the calculations indicate that between 1980 and 2011 men were 10\% more vulnerable with respect to their health status. However, the gender differences have been decreasing in recent years. Access of women to healthcare is decreasing with time, potentially decreasing the recovery potential of whole families. Women are more economically vulnerable than men in South Africa, as they are 16.3\% - 33\% more likely to be unemployed than men. Educational status of both genders in South Africa is comparable based on literacy and enrolment rates at primary and secondary level. On the other hand, men are five times more likely to suffer fatal injuries during disasters.

\section{Acknowledgments}

The authors would like to thank Rhodes University Research Committee for supporting the work in part (Grant no. 35215/2012).

\section{Competing interests}

The authors declare that they have no financial or personal relationship(s) which may have inappropriately influenced them in writing this paper.

\section{Authors' contributions}

R.T. (Rhodes University) was responsible for the manuscript writing, model development and took part in performing the relevant calculations. T.G.C. (Rhodes University) assisted with collecting the background literature, the data collection and contributed to performing some of the transport accident calculations. The research is conducted as part of T.G.C.'s (Rhodes University) research towards the Masters of Science in Pharmacy. C.S.S.S. provided input on the definition of gender and the role of gender differences in public health. This was crucial in the development of the model used to perform DII calculations. C.S.S.S. also took a leading role in the indication and gaining accessed to the relevant databases from which the necessary data was extracted, and played a crucial role in the finalising of the manuscript before submission to Jàmbá. 


\section{References}

Acker, J., 2002, 'Women and social stratification: a case of intellectual sexism', in S. Jackson \& S. Scott (eds.), Gender: a sociological reader, pp. 89-92, Routledge, New York.

Amsterdam Institute for Advanced Labour Studies, 2009, 'An overview of women's work and employment in South Africa: decision for life MDGs project country report no. 3', viewed 18 September 2012, from http://www.ituc-csi.org/IMG/pdf/ Country_Report_No3-South_Africa_EN.pdf

Arnold, M., 2008, The role of risk transfer and insurance in disaster risk reduction and climate change adaption, Commission on Climate Change and Development, Stockholm, Sweden.

Blaikie, P.M., Cannon, T., Davis, I. \& Wisner, B., 1994, At Risk: Natural Hazards, People's Vulnerability, and Disasters, Routledge, London.

Bradshaw, D., Groenewald, P., Laubscher, R., Nannan, N., Nojilana, B., Norman, R., Pieterse, D. \& Schneider, M., 2003, Initial burden of disease estimates for South Africa, 2000, Burden of Disease Research Unit, Medical Research Council, Cape Africa,
Town.

Cutter, S.L., 2001, American hazardscapes: The Regionalization of Hazards and Disasters, Joseph Henry Press, Washington, D.C.

Cutter, S.L., Boruff, B.J. \& Shirley, W.L., 2003, 'Social vulnerability to environmental hazards', Social Science Quarterly 84(2), 242-261. http://dx.doi.org/10.1111/15406237.8402002

Dorrington, R.E. \& Bradshaw, D., 2011, 'Maternal mortality in South Africa: lessons from a case study in the use of deaths reported by households in censuses and surveys', Journal of Population Research 28(1), 49-73. http://dx.doi.org/10.1007/ s12546-011-9050-9

Enarson, E., 2001, 'What women do: gendered labor in the Red River Valley flood', Environmental Hazards 3(1), 1-18. http://dx.doi.org/10.3763/ehaz.2001.0301

Food and Agricultural Organisation of the United Nations, 1997, 'Gender: the key to sustainability and food security', SD Dimensions, viewed 20 July 2012, from http://www.fao.org/sd/WPdirect/WPdoe001.htm

Haque, U., Hashizume, M., Kolivras, K.N., Overgaard, H.J., Das, B. \& Yamamoto, T., 2012 ,'Reduced death rates from cyclones in Bangladesh: What more needs to be done?', Bulletin of the World Health Organization 90(2), 150-156. http://dx.doi. org/10.2471/BLT.11.088302, PMid:22423166, PMCid:3302549

Hartman, D.A., 2002, viewed 22 February 2013, from http://www.lonestarreport.org/ LinkClick.aspx?fileticket=eKD4PVx6Eno\%3D\&tabid=162\&mid=688

Hautzinger, S., 2003, 'Researching men's violence: Personal reflections on ethnographic data', Men and Masculinities 6(1), 93-106. http://dx.doi. org/10.1177/1097184X03253139

Health Systems Trust (HST), 2011, 'Maternal mortality and morbidity - still not right', viewed 02 February 2012, from http://www.hst.org.za/news/maternal-mortalityviewed 02 February 2012, from

Hertz, T., 2004, 'Have minimum wages benefited South Africa's domestic service workers? African development and poverty reduction: the macro-micro linkage forum paper', viewed 18 September 2012, from http://www.dwrp.org.za/images/ stories/DWRP_Research/hertz_minimum_wages_for_domestics1.pdf

Hogan, M.C., Foreman, K.J., Naghavi, M., Ahn, S.Y., Wang, M., Makela, S.M. Lopez, A.D., Lozano, R. \& Murray, C.J.L., 2010, 'Maternal mortality for 181 countries, 1980-2008: a systematic analysis of progress towards Millennium Development 1980-2008: a systematic analysis of prog

Hunter, M., 2004, 'Masculinities, multiple-sexual-partners, and AIDS: the making and unmaking of Isoka in KwaZulu-Natal', Transformation 54, 123-153. http://dx.doi. org/10.1353/trn.2004.0019

Ingraham, C., 2002, 'The heterosexual imagery', in S. Jackson \& S. Scott (eds.), Gender: a sociological reader, pp. 79-84, Routledge, New York.

International Society of Red Cross and Red Crescent Societies, 2000, 'Introduction to Disaster Preparedness', viewed 07 August 2012, from http://www.ifrc.org/Global/ Publications/disasters/all.pdf

International Society of Red Cross and Red Crescent Societies, 2011, 'Public awareness and public education for disaster risk reduction: a guide', viewed 19 Septembe 2012, from http://www.ifrc.org/Global/Publications/disasters/all.pdf

Jewkes, R.K., Dunkle, K., Koss, M.P., Levin, J.P., Nduna, M., Jama, N. \& Sikweyiya, Y., 2006 , 'Rape perpetration by young, rural South African men: prevalence, patterns and risk factors', Social Science \& Medicine 63(11), 2949-2961. http://dx.doi. org/10.1016/j.socscimed.2006.07.027, PMid:16962222

Kapfudzaruwa, F. \& Sowman, M., 2009, 'Is there a role for traditional governance systems in South Africa's new water management regime?', Water SA 35, 683692. http://dx.doi.org/10.4314/wsa.v35i5.49195

Kelman, I., 2012, 'Disaster deaths', viewed 18 August 2012, from http://www. ilankelman.org/disasterdeaths.html

Kolbe, A.R., Hutson, R.A., Shannon, H., Trzcinski, E., Miles, B., Levitz, N., Puccio, M., James, L., Noel, J.R. \& Muggah, R., 2010, 'Mortality, crime and access to basic needs before and after the Haiti earthquake: A random survey of Port-au-Prince households', Medicine, Conflict and Survival 26(4), 281-297. http://dx.doi.org/10 .1080/13623699.2010.535279, PMid:21314081

Kuznets, S., 1955, 'Economic Growth and Income Inequality', American Economic Review 45(1), 1-28.

Laloë, V., 2004, 'Patterns of deliberate self-burning in various parts of the world: A review', Burns 30(3), 207-215. http://dx.doi.org/10.1016/j.burns.2003.10.018 PMid:15082345
Lerer, L.B. \& Matzopoulos, R., 1996, 'Meeting the challenge of railway injury in a South African city', Lancet 348(9028), 664-666. http://dx.doi.org/10.1016/S01406736(96)02100-9

Luyt, C.D., Muller, W.J., Wilhelmi, B.S. \& Tandlich, R., 2011, 'Health Implications of Flood Disaster Management in South Africa', in Proceedings of the 18th Annual Conference of the International Emergency Management Society, pp. 376-385, Bucharest, Romania.

MacLeod, C., 2007, 'The risk of phallocentrism in masculinities studies: how a revision of the concept of patriarchy may help', viewed 18 September 2012, from http:// www.pins.org.za/pins35/pins35_article03_Macleod.pdf

Mashele, P., 2004, 'Traditional leadership in South Africa's new democracy', Review of African Political Economy 31(100), 349-354.

Meel, B.L., 2008, 'Fatal road traffic accidents in the Mthatha area of South Africa, 1993-2004', South African Medical Journal 98(9), 716-719.

Morrell, R., 2007, 'Men, masculinities and gender politics in South Africa: a reply to MacLeod', viewed 16 September 2012, from http://www.pins.org.za/pins35/ pins35_article04_Morrell.pdf

National Disaster Management Centre (NDMC), 2006-2007, Annual Report 20062007, National Disaster Management Centre, Pretoria.

National Disaster Management Centre (NDMC), 2009, 'Draft Minutes: Meeting of National Disaster Management Advisory Forum (NDMAF)', meeting held on 13 August 2009, National Disaster Management Centre, Pretoria.

Ngubane, S.J., 2010, 'Gender roles in the African culture: implications for the spread of HIV/AIDS', Masters of Philosophy thesis, Stellenbosch University, Stellenbosch.

Nigg, J.M., Barnshaw, J. \& Torres, M.R., 2006, 'Hurricane Katrina and the Flooding of New Orleans: Emergent Issues in Sheltering and Temporary Housing', The ANNALS of the American Academy of Political and Social Science 604(1), 113-128. http:// dx.doi.org/10.1177/0002716205285889

Norris, F.H., Stevens, S.P., Pfefferbaum, B., Wyche, K.F. \& Pfefferbaum, R.L., 2008 'Community Resilience as a Metaphor, Theory, Set of Capacities, and Strategy for Disaster Readiness', American Journal of Community Psychology 41(1-2), 127150. http://dx.doi.org/10.1007/s10464-007-9156-6

North-West Provincial Government, 2002, 'State of the Provincial Environmental Report', viewed 02 September 2012, from http://www.nwpg.gov.za/soer/ FullReport/water.html\#ref1

Nyalunga, D., 2012, Dispelling the misconceptions and myths about gender, Democratic Development Programme, Durban.

Oyewumi, O., 1997, The invention of women: Making an African sense of western gender discourses, University of Minnesota Press, Minneapolis.

Prevention Web, 2011, 'South Africa - Disaster Statistics', viewed 10 November 2011 , from http://www.preventionweb.net/english/countries/statistics/?cid=160

Putnam, R.D., 2000, Bowling Alone: Collapse and Revival of the American Community, Simon \& Schuster, New York.

Service Delivery Review, 2009, 'Developing the public service and administrative capacity of the state in Africa', Service Delivery Review - A Learning Journal for the Public Service 7(1), 26-39.

Silberschmidt, M., 1992, 'Have men become the weaker sex? Changing life situations in the Kisii district, Kenya', Journal of Modern African Studies 30(2), 237-253. $\mathrm{http}: / / \mathrm{dx}$.doi.org/10.1017/S0022278X00010703

Silberschmidt, M., 2001, 'Disempowerment of men in rural and urban east Africa: Implications for male identity and sexual behaviour', World Development 29(4), 657-671. http://dx.doi.org/10.1016/S0305-750X(00)00122-4

South Africa, 1996, Mine Health and Safety Act 29 of 1996, viewed 03 September 2012, from http://www.info.gov.za/view/DownloadFileAction?id=70869

South African Regional Poverty Network, 2011, 'An overview of poverty and inequality in South Africa - Working Paper prepared for DFID (SA)', viewed 27 July 2012, from http://www.sarpn.org/documents/e0000006/page3.php

South African Weather Service, 2010, 'Daily extreme Temperatures and Rainfall over South Africa', viewed 07 March 2010, from http://metzone.weathersa.co.za/ images/PDF_docs/nr_extremes.pdf?1267994497687

Statistics South Africa (SSA), 2003, 'Mid-year population estimates 2003', Statistical release P0302, p. 10, Statistics South Africa, Pretoria.

Statistics South Africa (SSA), 2004, 'Mid-year population estimates 2004', Statistical release P0302, p. 39, Statistics South Africa, Pretoria.

Statistics South Africa (SSA), 2006, 'Adult mortality (age 15-64) based on death notification data in South Africa: 1997-2004', Statistical Report no. 03-09-05, p. 200, Statistics South Africa, Pretoria.

Statistics South Africa (SSA), 2009a, 'Mining industry, 2009', Report No. 20-01-02 (2001-2006), p. 33, Statistics South Africa, Pretoria.

Statistics South Africa (SSA), 2009b, 'Road Traffic Accident Deaths in South Africa, 2001-2006: Evidence from death notification', Report No. 03-09-07 (2001-2006), Statistics South Africa, Pretoria.

Statistics South Africa (SSA), 2009c, 'Mid-year population estimates 2009', Statistical release P0302, p. 17, Statistics South Africa, Pretoria.

Statistics South Africa (SSA), 2010, 'Social profile of South Africa, 2002-2009', Report No. 03-19-00, p. 106, Statistics South Africa, Pretoria.

Statistics South Africa (SSA), 2011a, 'General household survey 2010 (revised version)', Statistical release P0318, Statistics South Africa, Pretoria.

Statistics South Africa (SSA), 2011b, 'Mortality and causes of death in South Africa, 2009: Findings from death notification', Statistical release P0309.3, Statistics South Africa, Pretoria. 
Statistics South Africa (SSA), 2012, 'Quarterly Labour Force Survey Quarter 1, 2012', Statistical release P0211, Statistics South Africa, Pretoria.

The Legatum Prosperity Index, 2011, viewed 09 November 2011, from http:// http:// www.scribd.com/doc/76417013/Legatum-Prosperity-Index-2011

Tierney, K.J., Lindell, M.K. \& Perry, R.W., 2001, Facing the Unexpected: Disaster Preparedness and Response in the United States, Joseph Henry Press, Washington, D.C.

United Nations, 2008, Disaster Preparedness for Effective Response: Guidance and indicator package for implementing priority five of the Hyogo Framework, The United Nations Office for Coordination of Humanitarian Affairs, Geneva, Switzerland.

United Nations, 2012, 'Healthy Life Expectancy at Birth', viewed 16 August 2012, from http://unstats.un.org/unsd/demographic/products/socind/

United Nations (UNRW), 1995, 'The World's Women: 1995 Trends and Statistics', Social Statistics Series $K$ No.12, United Nations, New York.

United Nations (UNRW), 2000, 'The World's Women: 2000 Trends and Statistics', Department of Economic and Social Affairs, United Nations, New York.

United Nations (UNRW), 2005, 'The World's Women: 2005 - Progress in Statistics', Department of Economic and Social Affairs - Statistics Division, United Nations, New York.

United Nations (UNRW), 2010, 'The World's Women: 2010 Trends and Statistics', Department of Economic and Social Affairs - Statistics Division, United Nations, New York.

United Nations Development Programme, 2008, UNDP Development Indices, UNESCO Institute for Statistics, Geneva, Switzerland.
United Nations Development Programme, 2010, 'Gender and Disasters', viewed 03 August 2012, from http://www.undp.org/content/dam/undp/library/crisis\%20 prevention/disaster/7Disaster\%20Risk\%20Reduction\%20-\%20Gender.pdf

United Nations Human Development Index (HDI), 2012, viewed 23 July 2012, from http://hdrstats.undp.org/en/indicators/103106.html

United Nations Statistical Indicators, 2012, 'Statistics and indicators on women and men', viewed 27 July 2012, from http://unstats.un.org/unsd/demographic/ products/indwm/

Walby, S., 2002, 'Gender, class and stratification: towards a new approach', in S. Jackson \& S. Scott (eds.), Gender: a sociological reader, pp. 93-96, Routledge, New York.

West, C. \& Zimmerman, D.H., 2002, 'Doing gender', in S. Jackson \& S. Scott (eds.), Gender: a sociological reader, pp. 42-47, Routledge, New York.

Widgren, J., 1995, 'Global arrangements to combat trafficking in migrants', Migration World 23(3), 19-25.

Williams, S.L., Williams, D.R., Stein, D.J., Seedat, S., Jackson, P.B. \& Moomal, H., 2007 , 'Multiple traumatic events and psychological distress: The South Africa stres and health study', Journal of Traumatic Stress 20(5), 845-855. http://dx.doi. org/10.1002/jts.20252

World Health Organisation (WHO), 2012a, 'Maternal mortality', viewed 16 August 2012, from http://www.who.int/mediacentre/factsheets/fs348/en/

World Health Organisation (WHO), 2012b, 'Chapter XX: External causes of morbidity and mortality (V01-Y98). Sequelae of external causes of morbidity and mortality (Y85-Y89)', viewed 18 August 2012, from http://apps.who.int/classifications/ apps/icd/icd10online2007/index.htm?navi.html 